\title{
Detection of dust aerosol by combining CALIPSO active lidar and passive IIR measurements
}

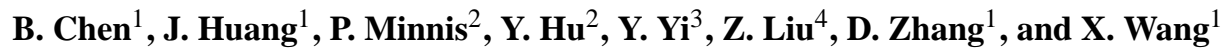 \\ ${ }^{1}$ Key Laboratory for Semi-Arid Climate Change of the Ministry of Education, College of Atmospheric Science, Lanzhou \\ University, Lanzhou, 730000, China \\ ${ }^{2}$ NASA Langley Research Center, Hampton, VA, 23666, USA \\ ${ }^{3}$ Science Systems and Applications Incorporated, Hampton, VA, 23666, USA \\ ${ }^{4}$ National Institute of Aerospace, Hampton, VA, 23666, USA
}

Received: 15 December 2009 - Published in Atmos. Chem. Phys. Discuss.: 9 February 2010

Revised: 29 April 2010 - Accepted: 5 May 2010 - Published: 6 May 2010

\begin{abstract}
The version 2 Cloud-Aerosol Lidar and Infrared Pathfinder Satellite Observations (CALIPSO) dust layer detection method, which is based only on lidar measurements, misclassified about $43 \%$ dust layers (mainly dense dust layers) as cloud layers over the Taklamakan Desert. To address this problem, a new method was developed by combining the CALIPSO Cloud-Aerosol Lidar with Orthogonal Polarization (CALIOP) and passive Infrared Imaging Radiometer (IIR) measurements. This combined lidar and IR measurement (hereafter, CLIM) method uses the IIR tri-spectral IR brightness temperatures to discriminate between ice cloud and dense dust layers, and lidar measurements alone to detect thin dust and water cloud layers. The brightness temperature difference between 10.60 and $12.05 \mu \mathrm{m}\left(\mathrm{BTD}_{11-12}\right)$ is typically negative for dense dust and generally positive for ice cloud, but it varies from negative to positive for thin dust layers, which the CALIPSO lidar correctly identifies. Results show that the CLIM method could significantly reduce misclassification rates to as low as $\sim 7 \%$ for the active dust season of spring 2008 over the Taklamakan Desert. The CLIM method also revealed $18 \%$ more dust layers having greatly intensified backscatter between 1.8 and $4 \mathrm{~km}$ altitude over the source region compared to the CALIPSO version 2 data. These results allow a more accurate assessment of the effect of dust on climate.
\end{abstract}

Correspondence to: $\mathrm{B}$. Chen

(chenb03@1zu.cn)

\section{Introduction}

Mineral dust emitted from arid and semi-arid regions plays an important role in climate by altering the radiation balance in the atmosphere through the scattering and absorption of solar radiation, and by absorbing and emitting outgoing longwave radiation (Tegen, 2003; Huang et al., 2006a; Slingo et al., 2006), a phenomenon termed as the "direct aerosol effect". They can also cause changes in cloud properties, such as the number concentration and size of cloud droplets, which can alter both cloud albedo and cloud lifetime (Albrecht, 1989; Twomey et al., 1984; Huang et al., 2006b; Su et al., 2008), a phenomenon termed as the "indirect aerosol effect". These impacts are very difficult to quantify and, thus, a large uncertainty exists in the role that dust aerosols play in climate variability. The Gobi Deserts in Mongolia and northern China, and the Taklamakan Desert in China, are the two dominant dust source regions in East Asia. Dust aerosols generated in the Taklamakan and Gobi areas are usually transported eastward by the prevailing westerlies and can pass over China, North and South Korea, and Japan, (Iwasaka et al., 1983; Zhang et al., 1997; Murayama et al., 2001; Uno et al., 2001; Natsagdorj et al., 2003) and sometimes are carried farther across the Pacific Ocean reaching North America (Uno et al., 2001; Husar et al., 2001; Sassen, 2002).

The Cloud-Aerosol Lidar and Infrared Pathfinder Satellite Observations (CALIPSO) mission was launched successfully in April 2006 (Winker et al., 2006, 2007) and provides valuable information on dust aerosols, helping clarify their climatic role and radiative effects on a global scale.

Published by Copernicus Publications on behalf of the European Geosciences Union. 
Table 1. Window channels characterizations of Infrared Imaging Radiometer (IIR).

\begin{tabular}{lllll}
\hline Channel & Window $(\mu \mathrm{m})$ & Central wavelength $(\mu \mathrm{m})$ & Spectral interval $(\mu \mathrm{m})$ & Resolution $\left(\mathrm{km}^{2}\right)$ \\
\hline $\mathrm{IR}_{08}$ & $8-13$ & 08.65 & $08.25-09.05$ & 1 \\
$\mathrm{IR}_{11}$ & $8-13$ & 10.60 & $10.20-11.00$ & 1 \\
$\mathrm{IR}_{12}$ & $8-13$ & 12.05 & $11.60-12.40$ & 1 \\
\hline
\end{tabular}

The primary payload on the CALIPSO satellite is a twowavelength, polarization-sensitive backscatter lidar known as the Cloud-Aerosol Lidar with Orthogonal Polarization (CALIOP). Among the many instruments carried by the socalled A-Train constellation of satellites, CALIOP is unique in its ability to measure high-resolution vertical profiles of both clouds and aerosols within the Earth's atmosphere all over the world (Winker et al., 2004). CALIOP data have been used to study the occurrence of Tibetan dust plumes (Huang et al., 2007a), the long-range transport of dust aerosols ( $\mathrm{Z}$. Liu et al., 2008; Huang et al., 2008), the height-resolved global distribution of dust aerosols (D. Liu et al., 2008), long-distance dust aerosol vertical distribution over Shanghai, China, (Chen et al., 2008), the Saharan dust outflow (Generoso et al., 2008), and Taklamakan dust aerosol radiative heating (Huang et al., 2009). Kim et al. (2008) confirmed that the CALIPSO algorithms discriminate clouds and aerosols and detect the layer top and base altitudes reliably by comparing CALIOP and ground-based lidar data at a site far from the dust source, in Seoul, Korea. However, as pointed out by Z. Liu et al. (2009), there were a few cases of erroneous cloud and aerosol classification in the current (as of this writing) CALIPSO data release (Version 2). The Version-2 algorithm employs a cloud and aerosol discrimination (CAD) scheme based on three-dimensional (3-D) probability distribution functions (PDFs) of attenuated backscatter, the layer-integrated color ratio, and the mid-layer altitude. The 3-D PDFs were developed from the Shuttle-borne Lidar In-space Technology Experiment (LITE) and airborne lidar measurements (Liu et al., 2004). A very dense dust layer near or over a source region is a typical scene that can be misclassified as cloud by the Version 2 CAD algorithm (V2CAD) because the dust layer characteristics are in a region that overlaps with the cloud PDFs in the selected 3-D space. Although the fraction of cloud and aerosol misclassifications due to dense dust is very small globally, it can be frequent during active dust seasons over source areas.

This study attempts to develop a different approach that takes advantage of the simultaneous lidar and Infrared Imaging Radiometer (IIR) measurements provided by CALIPSO. Infrared (IR) measurements have long been used to detect dust storms (Shenk et al., 1974; Legrand et al., 1985, 2001; Ackerman et al., 1997). By comparing the brightness temperature difference (BTD) between the 8 and $11 \mu \mathrm{m}$ channels with that between the 11 and $12 \mu \mathrm{m}$ channels, dust can be discriminated from clear sky over both the ocean and land. This IR BTD method is very effective for the detection of dust storms (Roskovensky et al., 2003, 2005; El-Askary et al., 2006; Legrand et al., 2001), but often fails to detect thin dust layers, which may be far from the dust source region. For global dust plume detection, the best approach may be to combine lidar and IR measurements.

Section 2 presents the data used in this study. Two test cases are described in Sect. 3, and the dust identification method is outlined in Sect. 4. Section 5 discusses the validation and error analysis of data for 2008, while Sect. 6 describes dust occurrence and vertical profiles over the Taklamakan Desert. Finally, the conclusions and discussions are given in Sect. 7.

\section{Satellite and surface data}

\subsection{CALIPSO data}

The CALIPSO payload consists of the CALIOP, the IIR, and the Wide Field Camera. CALIOP is designed to acquire vertical profiles of elastic backscatter at two wavelengths (532 and $1064 \mathrm{~nm}$ ) from a near nadir-viewing geometry during both day and night phases of the orbit. In addition to total backscatter at the two wavelengths, CALIOP also provides profiles of linear depolarization at $532 \mathrm{~nm}$.

The IIR, France's contribution to the CALIPSO payload, was developed by the company SODERN, with the Centre National d'Études Spatiales as the prime contractor. The instrument contains a three-channel imaging radiometer in the thermal infrared at $8.65 \mu \mathrm{m}, 10.60 \mu \mathrm{m}$, and $12.05 \mu \mathrm{m}$ (see Table 1). The IIR images provide context to the lidar measurements and allow for co-registration with the MODIS multispectral radiometer aboard Aqua. This paper uses CALIOP level 1B and level 2 VFM data (version 2), and IIR level 2 Swath Beta (version 2).

\subsection{CloudSat data}

The CloudSat mission, launched on 28 April 2006 as part of the NASA Earth System Science Pathfinder Program and of the A-Train constellation, flies the first spaceborne millimeter wavelength radar (Stephens et al., 2002). The Cloud Profiling Radar (CPR) on CloudSat operates at a frequency of $94 \mathrm{GHz}$ and points nominally in the nadir direction only. 
The CPR emits a pulse of $3.3 \mathrm{~ms}$ in duration leading to a vertical resolution of approximately $480 \mathrm{~m}$. The backscattered signal is oversampled to produce a range gate spacing of $240 \mathrm{~m}$. CloudSat level 2B-CLDCLASS data were utilized.

\subsection{MODIS data}

Aqua was launched on 4 May 2002. This satellite has a nearpolar low-Earth orbit and carries six Earth-observing instruments that collect a variety of global data. The Moderate Resolution Imaging Spectroradiometer (MODIS) is one of these instruments. MODIS is a 36-band spectroradiometer that measures visible and infrared radiation. Aqua MODIS level-1B $500 \mathrm{~m}$ calibrated radiances were used in this study.

\subsection{Surface observations}

Surface meteorological data, used to independently identify dust conditions, were obtained from the Gansu Meteorological Bureau in China and include daily standard surface observations and daily charts.

\subsection{Data selection}

All daytime data were analyzed over the Taklamakan Desert ( $36^{\circ}$ to $42^{\circ} \mathrm{N}, 72^{\circ}$ to $92^{\circ} \mathrm{E}$ ) during spring (March to May) in 2007 and 2008. To simplify the analysis and for validation against other satellite data and surface observations, only single feature layer (the spacing of all adjacent features for one CALIOP profile are below $0.6 \mathrm{~km}$ ) data were used in this study.

\section{Case studies}

A dust storm (case 1, 22 April 2007) and a floating dust event (case 2, 10 May 2007) over the Taklamakan Desert are examined in this section.

\subsection{Case 1}

On 22 April 2007, a dust storm occurred over the Taklamakan. Figure 1a shows the ground station observations at 06:00 UTC, about $1.5 \mathrm{~h}$ before the CALIPSO passed overhead. Of the ground stations near the CALIPSO track, 21 stations reported blowing dust with corresponding observation visibilities around $1 \mathrm{~km}$. Seven stations reported blowing dust with visibilities of about $2 \mathrm{~km}$. Two stations reported dust storms and visibilities less than $1 \mathrm{~km}$. The wind speeds were generally between 7 and $12 \mathrm{~m} / \mathrm{s}$, but at some stations, they exceeded $13 \mathrm{~m} / \mathrm{s}$. Such wind speeds are sufficient to produce and support dust storms (Chen et al., 1995). The Aqua MODIS red-green-blue color image shows distinct dust plumes between 37.3 and $42.0^{\circ} \mathrm{N}$ (Fig. 1b).

Independent observations from the nadir-viewing CloudSat radar (Fig. 2a) did not show any clouds over this region.
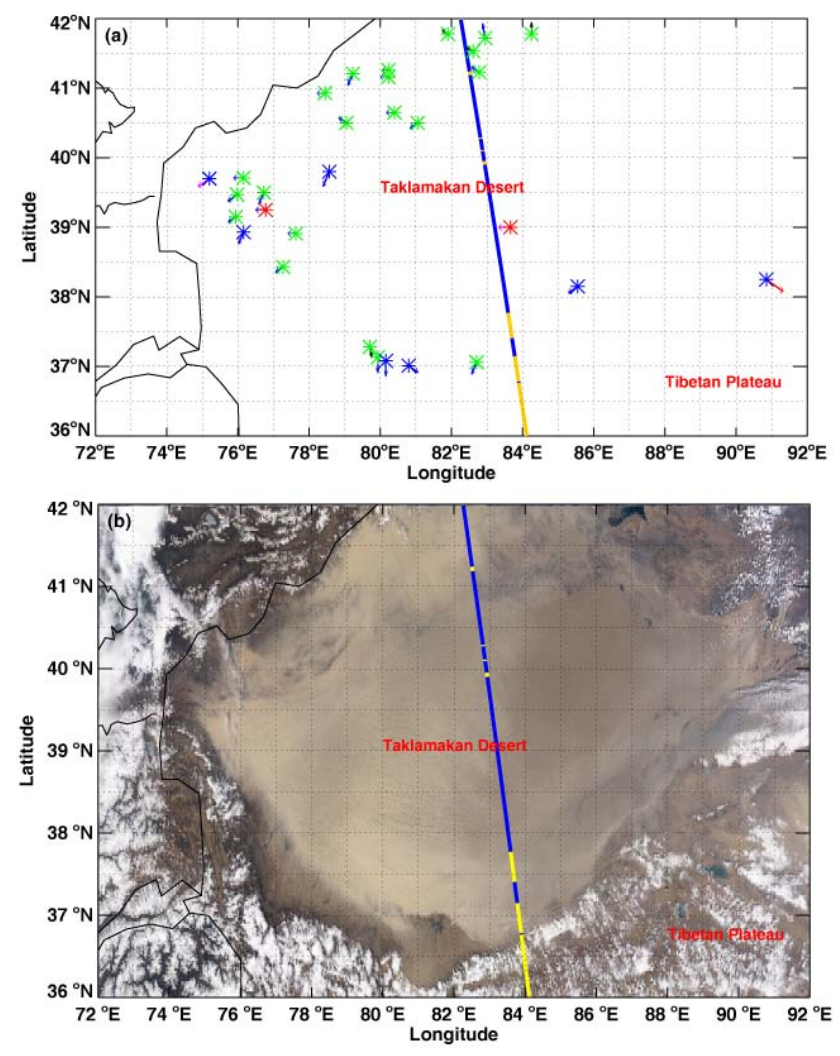

Fig. 1. (a) Surface station observations for 06:00 UTC, 22 April 2007. The red asterisk represents dust storms, blue asterisk denotes blowing dust, and green asterisk indicates floating dust. Surface wind speeds indicated by arrows: black $(<2 \mathrm{~m} / \mathrm{s})$, blue ( 3 to $6 \mathrm{~m} / \mathrm{s}$ ), purple (7 to $12 \mathrm{~m} / \mathrm{s}$ ), and red $(>13 \mathrm{~m} / \mathrm{s}$ ). (b) True color Aqua MODIS image over Taklamakan desert for 22 April 2007. Red, green, and blue are given by intensities for the $0.65,0.56$, and $0.47 \mu \mathrm{m}$ channels, respectively. The yellow line shows CALIPSO nadir track, and blue segments present single feature layer.

CloudSat observations were taken $12.3 \mathrm{~s}$ ahead of CALIPSO. The corresponding CALIPSO lidar $532 \mathrm{~nm}$ backscatter measurements and feature mask (FMK) derived by V2-CAD are presented in Fig. $2 b$ and c. Figure $2 b$ shows a strong $532 \mathrm{~nm}$ attenuated backscatter layer with grayish color, similar to that of optically thin clouds, over the track shown in Fig. 1. The maximum 532-nm attenuated backscatter coefficient values can reach $0.014 \mathrm{~km}^{-1} \mathrm{sr}^{-1}$ at about $2.1 \mathrm{~km}$ above mean sea level (MSL). This strong backscatter layer was classified as cloud by the CALIPSO V2-CAD algorithm (Fig. 2c). However, as can be seen from Figs. 1 and 2a, this layer could have been a dense dust layer rather than a cloud layer.

\subsection{Case 2}

The second case, presented in Figs. 3 and 4, was a floating dust event. As can be seen in Fig. 3a, there were 14 reports of floating dust, 2 of blowing dust, and 1 of a dust storm from surface stations around the CALIPSO track region $\left(38^{\circ}\right.$ 

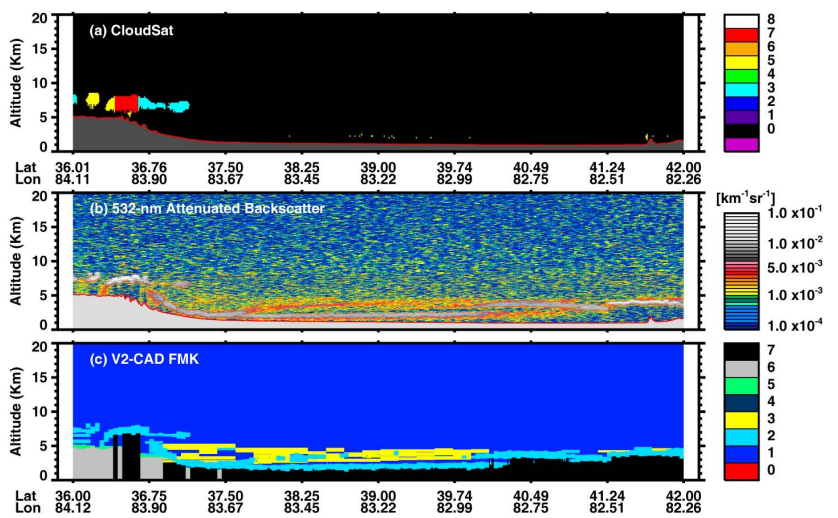

Fig. 2. (a) CloudSat level 2 cloud scenario classification product, and color bar indicates feature type $(0=$ invalid, $1=$ high cloud, $2=\mathrm{As}, 3=\mathrm{Ac}, 4=\mathrm{St}, 5=\mathrm{Sc}, 6=\mathrm{Cu}, 7=\mathrm{Ns}$, and $8=$ Deep convective clouds). (b) CALIPSO altitude-orbit cross section measurements of 532-nm total attenuated backscatter intensity $\left(\mathrm{km}^{-1} \mathrm{sr}^{-1}\right)$. (c) V2-CAD method vertical Feature Mask (FMK) measurements, Color bar indicates feature type (feature type: $0=$ invalid, $1=$ clear air, 2=cloud, $3=$ aerosol, $4=$ stratospheric feature, $5=$ surface, $6=$ subsurface, $7=$ no signal), in the CALIOP current version 2.01 data for 22 April 2007.

to $42^{\circ} \mathrm{N}$ ). Neither MODIS (Fig. 3b) nor CloudSat (Fig. 4a) detected clouds along this track. CALIPSO measured a strong backscatter layer. The maximum 532-nm attenuated backscatter coefficient value of the dust aerosol profile reached $0.008 \mathrm{~km}^{-1} \mathrm{sr}^{-1}$ about $2.6 \mathrm{~km}$ above MSL (Fig. $4 \mathrm{~b}$ ). Figure $4 \mathrm{c}$ shows that the backscatter layer was misidentified as cloud by the CALIPSO V2-CAD algorithm.

Both cases study demonstrate that the CALIPSO V2-CAD algorithm could not properly identify a dense dust layer over the dust source due to the stronger backscatter. This result is the same as that reported by Z. Liu et al. (2004, 2009). To address this problem, a new method was developed that combines the CALIPSO active lidar and passive IIR measurements.

\section{Development of the combined algorithm}

A new dust index (DI $\mathrm{DLIM}_{\mathrm{C}}$ ) is developed using a combination of lidar and multispectral IR data. This new index is based on the principles of the older, separate IR and lidar dust indices and is tuned using independent dust and cloud measurements from CALIPSO, CloudSat, MODIS, and the surface taken during spring 2007. It is then evaluated over the same region using data from spring 2008.

\subsection{IR method}

Ackerman (1997) found that BTDs between 11 and $12 \mu \mathrm{m}$ $\left(\mathrm{BT}_{11-12}\right)$ were sensitive to dust storms. The absorption by atmospheric gases at 11 and $12 \mu \mathrm{m}$ is small, and dense
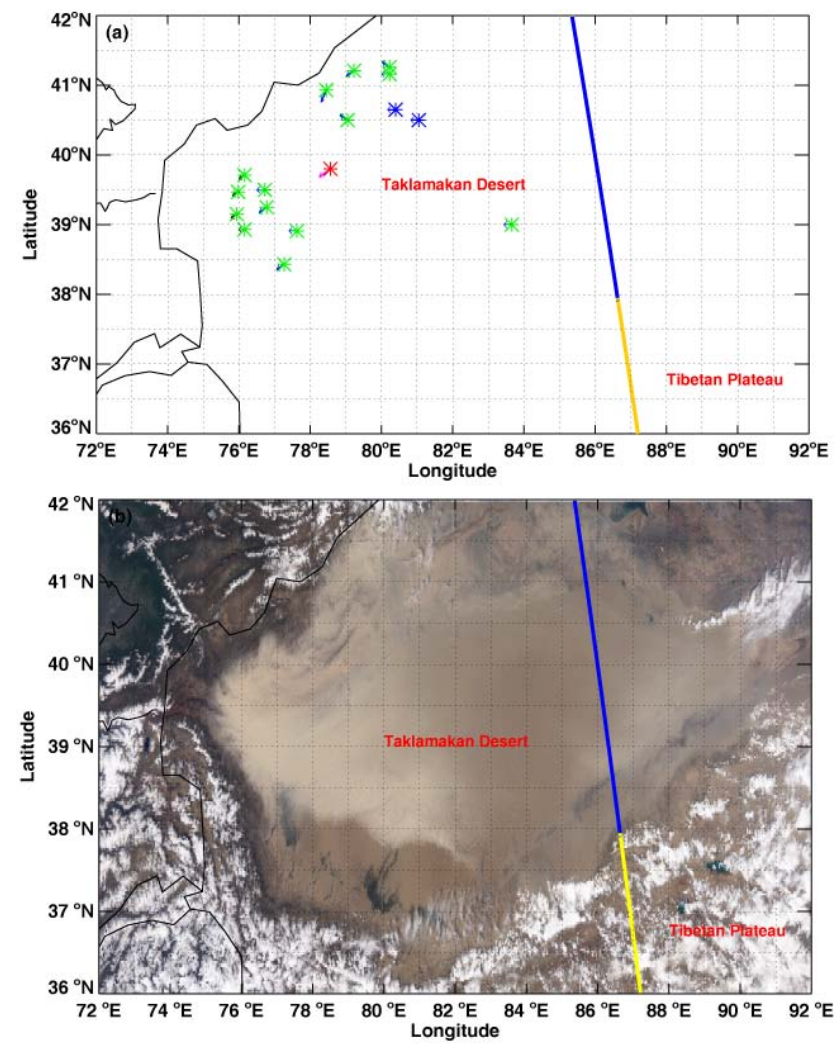

Fig. 3. Same as Fig. 1 except for 10 May 2007.
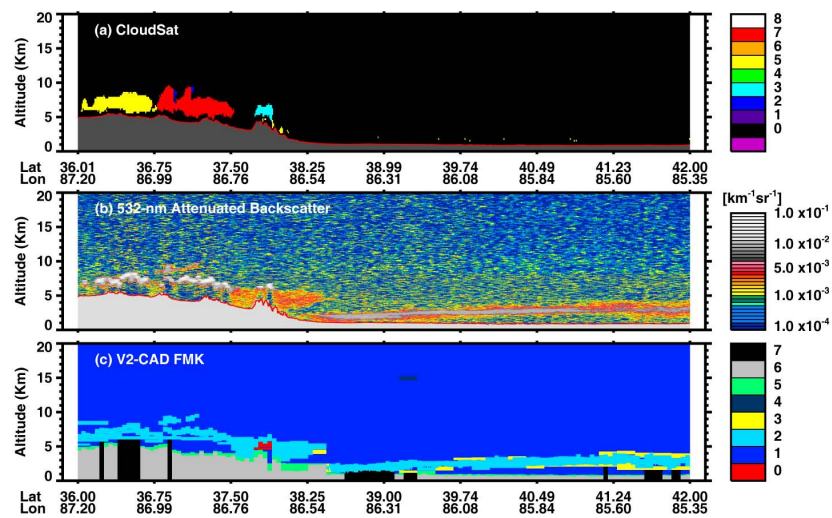

Fig. 4. Same as Fig. 2 except for 10 May 2007.

dust has a higher emissivity at $12 \mu \mathrm{m}$ than at $11 \mu \mathrm{m}$. The BTD $_{11-12}$ threshold has been widely used to differentiate dust from other aerosols and cloud (Shenk et al., 1974; Ackerman, 1997; Legrand et al., 1985, 2001; Zhang et al., 2006). Zhang et al. (2006) developed a dust storm mask algorithm from MODIS observations by combining $\mathrm{BTD}_{8-11}$, which is the optimal threshold to determine the strength of dust storm, and $\mathrm{BTD}_{11-12}$, and setting $-0.5 \mathrm{~K}$ as the dust storm threshold for BTD $11-12$. By following Zhang et al. (2006), the dust index (DI) by the IIR measurement (IIRM) method (DI IIRM) 
that distinguishes dust storm aerosols from those of cloud is defined as follows:

$D I_{\text {IIRM }}=A_{0}+A_{1} \cdot \mathrm{BTD}_{1}+A_{2} \cdot \mathrm{BTD}_{2}$

In Eq. (1), BTD 1 is the brightness temperature difference between the IIR 10.60 and $12.05 \mu$ m channels, and $\mathrm{BTD}_{2}$ is the brightness temperature difference between the IIR 8.65 and $11.60 \mu \mathrm{m}$ channels, and $A_{0}$ to $A_{2}$ are coefficients.

\subsection{Lidar method}

The current CALIPSO lidar method (V2-CAD) is based on experience acquired from airborne lidar measurements and the LITE mission (Winker et al., 1996). The CALIPSO feature-finding algorithm is driven by a profile-scanning engine originally developed for ground-based observations (Winker et al., 1994) and later adapted for space using LITE data (Platt et al., 1999). The V2-CAD method is divided into two modules, which have the general functions of detecting layers and classifying them by type. These modules are the selective iterated boundary locator (SIBYL) algorithm and the scene classification algorithm (SCA). The SIBYL is adapted to the detection of weak features lying beneath strong ones using a dynamic threshold scheme (Vaughan et al., 2004). It estimates layer optical depths, which are then used to correct the profile data for the signal attenuation of overlying features. The SCA identifies layers as either cloud or aerosol, based primarily on scattering strength and the spectral dependence of the lidar backscattering. The algorithm (V2-CAD) uses PDFs of the layer mean attenuated backscatter at $532 \mathrm{~nm}$, the layer-integrated from 1064 to 532$\mathrm{nm}$ volume color ratio, and the mid-layer altitude (Z. Liu et al., 2004).

To facilitate comparison with other methods, we define a dust index of the lidar method (LidarM) as:

$\mathrm{DI}_{\text {LidarM }}=$

$B_{0}+B_{1} \cdot \beta \cdot 100+B_{2} \cdot \delta \cdot 10+B_{3} \cdot \chi \cdot 10+B_{4} \cdot \varepsilon+B_{5} \cdot \zeta$

where $\beta$ is the layer mean attenuated backscatter at $532 \mathrm{~nm}$, $\delta$ is the layer mean depolarization ratio (layer-integrated perpendicular-to-parallel attenuated backscatter at $532 \mathrm{~nm}$ ), $\chi$ is the layer-integrated 1064 to $532-\mathrm{nm}$ volume color ratio, $\varepsilon$ is the feature layer top altitude, $\zeta$ is the feature layer base altitude above MSL, and $B_{0}$ to $B_{5}$ are the coefficients for Eq. (2). To compare with V2-CAD, one more parameter is added in the $\mathrm{DI}_{\text {lidarM }}$ : i.e., the layer mean depolarization ratio. In addition, the mid-layer altitude in the V2-CAD method is replaced by the layer top and the layer base altitudes in the $\mathrm{DI}_{\text {lidarM }}$.

\subsection{Combined method}

As Z. Liu et al. (2004) noted, the lidar method misidentifies almost all dense dust as cloud over source regions, but it can detect thin dust layers accurately. In contrast, the IR

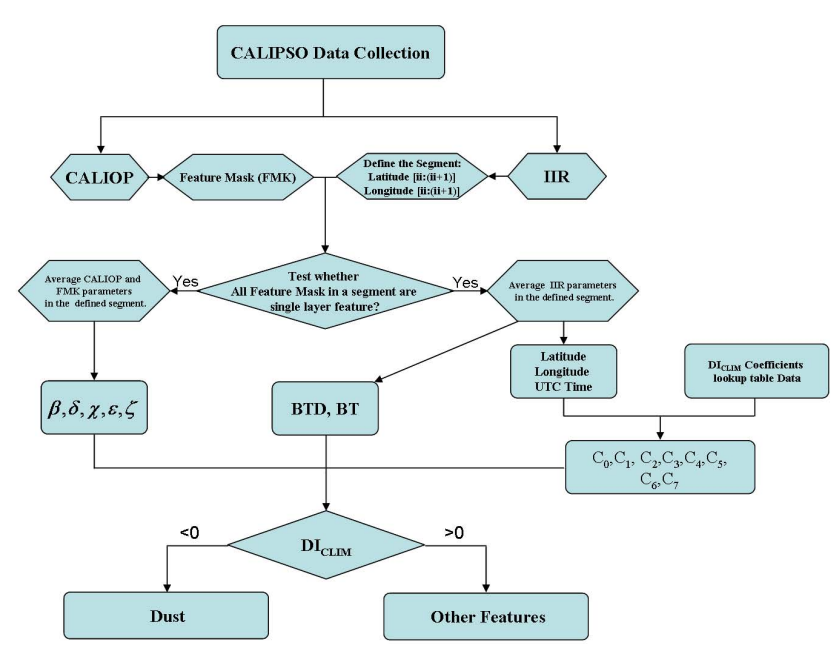

Fig. 5. CLIM method dust aerosol detection flow chart for a segment.

method can detect dense dust accurately. Thus combining both the methods allows the detection of both thin and dense dust aerosols.

To combine the lidar and IR methods (CLIM), the dust index by the CLIM method ( $\mathrm{DI}_{\mathrm{CLIM}}$ ) is expressed as:

$$
\begin{aligned}
& D I_{\mathrm{CLIM}}=C_{0}+C_{1} \cdot \mathrm{BTD}_{1}+C_{2} \cdot \mathrm{BTD}_{2}+ \\
& C_{3} \cdot \beta \cdot 100+C_{4} \cdot \delta \cdot 10+ \\
& C_{5} \cdot \chi \cdot 10+C_{6} \cdot \varepsilon+C_{7} \cdot \zeta
\end{aligned}
$$

Here, $\mathrm{BTD}_{1}$, and $\mathrm{BTD}_{2}$ are the same as in Eq. (1); $\beta, \delta, \chi$, $\varepsilon$, and $\zeta$ are the same as in Eq. (2); and $C_{0}$ to $C_{7}$ are the coefficients for Eq. (3).

Figure 5 shows a flowchart of the CLIM method. As can be seen, a feature segment (i.e., a single IIR pixel) between the adjacent IIR points (ii to $i i+1$ ) is selected, and feature masks are obtained from CALIOP using the SIBYL algorithm (Vaughan et al., 2004). Because the IIR and CALIOP horizontal resolutions are 1.0 and $0.333 \mathrm{~km}$, respectively, every segment includes three CALIOP profiles. The singlelayer program is used to estimate all the profiles in a segment, whether or not they are single-layer, by the method that the vertical spacing of all adjacent feature layers in a profile is less than $0.6 \mathrm{~km}$. If all the feature layers of the profiles are single, CALIOP, FMK, and IIR parameters are averaged in the segment, and $\mathrm{DI}_{\mathrm{CLIM}}$ coefficients are selected from database lookup tables by provided the latitude, longitude, and UTC time. Equation (3) is solved for each IIR pixel using the coefficients and mean parameters, giving a new CLIM mask that distinguishes dust aerosols $\left(\mathrm{DI}_{\mathrm{CLIM}}<0\right)$ from other features $\left(\mathrm{DI}_{\mathrm{CLIM}}>0\right)$.

The coefficients used in Eq. (3), were determined through Fisher discriminate analysis (Mika et al., 1999) using the independent data from spring 2007. As Table 2 shows, the features of each IIR pixel are identified as clouds if both the V2-CAD and CloudSat observations cloud. The feature is 
Table 2. Independent cloud and dust aerosol differentiation method using CALIOP, CloudSat, MODIS and Surface stations observations.

\begin{tabular}{lllll}
\hline CALIOP & CloudSat & MODIS & Surface stations & Category \\
\hline Cloud & Cloud & $/$ & $/$ & Cloud \\
Dust & No cloud & $/$ & $/$ & Dust aerosol \\
/ & No cloud & No cloud & Dust weather & Dust aerosol \\
\hline
\end{tabular}

Table 3. Coefficients in Eq. (3).

\begin{tabular}{lllllllll}
\hline Coefficient & $\mathrm{C}_{0}$ & $\mathrm{C}_{1}\left(\mathrm{~K}^{-1}\right)$ & $\mathrm{C}_{2}\left(\mathrm{~K}^{-1}\right)$ & $\mathrm{C}_{3}(\mathrm{~km} \cdot \mathrm{sr})$ & $\mathrm{C}_{4}$ & $\mathrm{C}_{5}$ & $\mathrm{C}_{6}\left(\mathrm{Km}^{-1}\right)$ & $\mathrm{C}_{7}\left(\mathrm{Km}^{-1}\right)$ \\
\hline Value & -0.59 & 0.275 & 0.098 & 0.595 & -0.549 & 0.000 & 0.243 & 0.315 \\
\hline
\end{tabular}
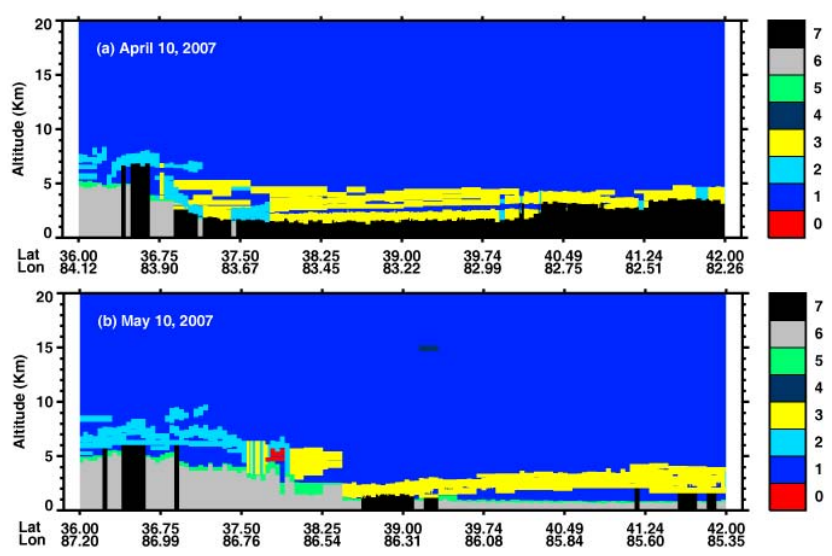

Fig. 6. CLIM method feature mask for the first case, (a) 22 April 2007, and the second case, (b) 10 May 2007, respectively.

identified as dust aerosol, if CloudSat observes no cloud and the V2-CAD identifies dust aerosol, or if neither CloudSat nor MODIS detects cloud and surface stations observe dust weather (dust storms, blowing and floating dust). The selection of no clouds by MODIS observations is based on manual classification using the true color MODIS images (Darmenov et al., 2005), as seen Fig. 1b and 3b, and the manual classification for MODIS data is used only for the region where CloudSat observes no cloud and surface stations report dust weather when CALIPSO passes. Altogether, 5185 cloud segments and 7883 dust aerosol segments were identified over the Taklamakan Desert during spring 2007. Table 3 lists the values of the coefficients in Eq. (3) determined by Fisher discriminate analysis from these data.

These coefficients weight the various input parameters used in Eq. (3). First, the depolarization ratio can distinguish certain features (including ice clouds and dust aerosol) from all others. Second, for dense features, the dense dust parameters, $\beta, \delta$, and $\chi$, are almost the same as for the same altitude ice clouds. However, the $\mathrm{BTD}_{11-12}$ is always negative for

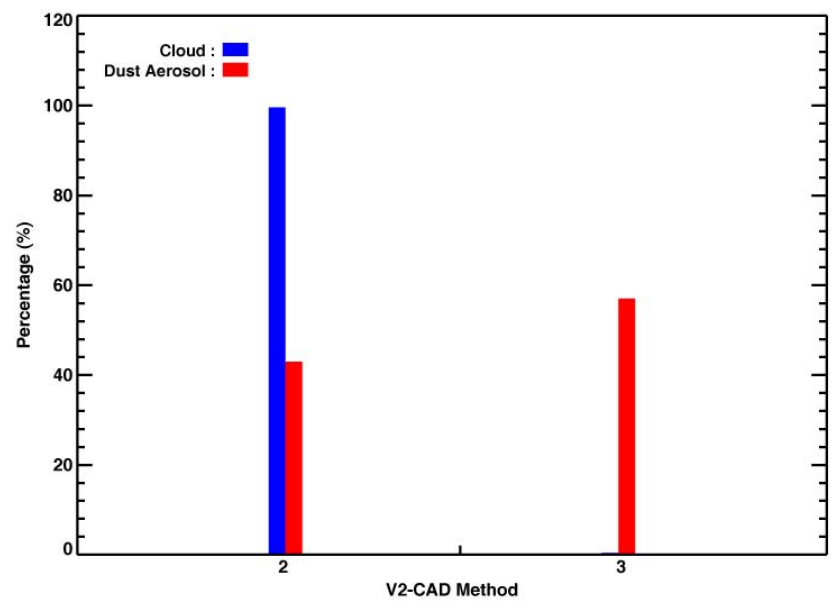

Fig. 7. Table 2 selection of cloud (blue bar) and dust aerosol (red bar) vs. V2-CAD method Feature Classification (feature type: $2=$ cloud, $3=$ aerosol) for spring 2008 .

dense dust and positive for ice cloud, and the dense dust can be distinguished from dense ice cloud by the CLIM method. For thin features, the BTD of dust aerosol and ice cloud may be almost the same over certain surfaces when surface infrared radiation can penetrate these features. However, for ice clouds, $\beta$ is larger and the layer altitude is higher, while for dust, $\beta$ is smaller and the layer altitude is lower; thus, based on these differences, the CLIM method can distinguish thin dust from ice cloud.

As discussed in Sect. 3 for cases 1 and 2, there was no cloud in the study region. The surface stations reported dust weather, but the V2-CAD method misclassified the dust aerosol as cloud. The CLIM method, however, can detect the dense dust aerosol, in agreement with the results of surface station observations, MODIS, and CloudSat, as shown in Fig. 6 for cases 1 and 2. 


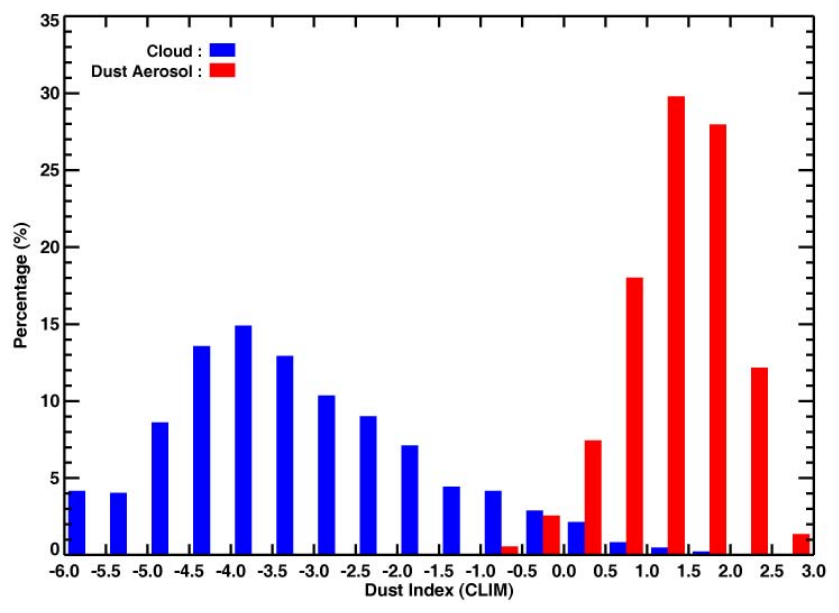

Fig. 8. Table 2 selection of cloud (blue) and dust aerosol (red) vs. CLIM method dust index for spring 2008.

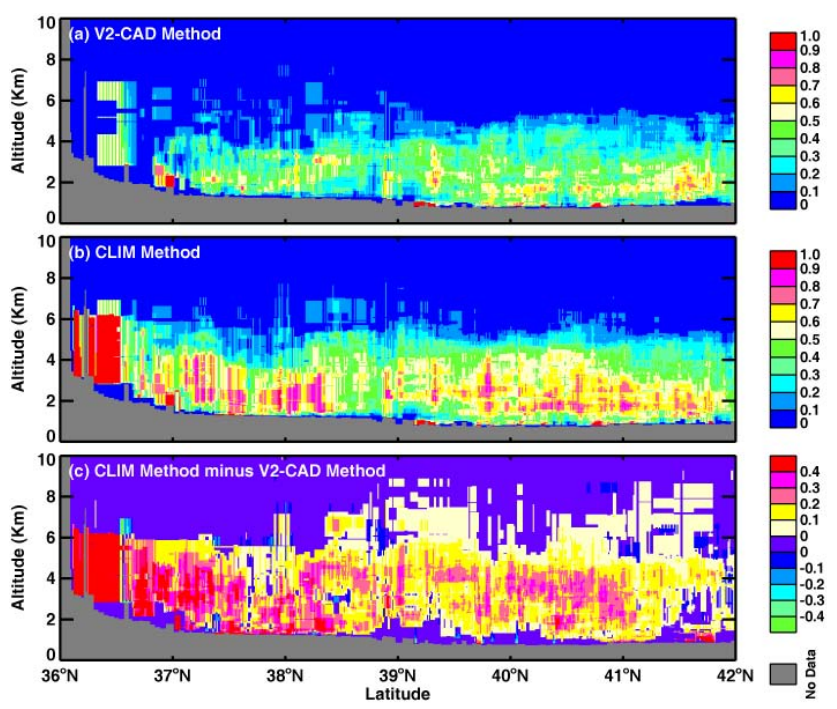

Fig. 9. Latitude mean vertical distributions of dust layer occurrence from CALIPSO observations by V2-CAD method (a), CLIM (b), and CLIM minus V2-CAD (c) over Taklamakan desert for elevations below $3 \mathrm{~km}$ during spring 2008.

\section{Validation and error analysis}

To validate the CLIM method, an independent dataset for the same region but from spring 2008 was selected to test the results. According to the Table 2 data selection steps, there were 6230 segments of cloud and 6818 segments of dust aerosol over the Taklamakan Desert during the daytime in spring 2008.

To test the detection methods under the same standard, the dust identification error $\left(R_{d}\right)$ was defined as follows:

$$
R_{\mathrm{d}}=N_{\mathrm{ed}}+N_{\mathrm{ec}} / N_{\mathrm{d}}
$$

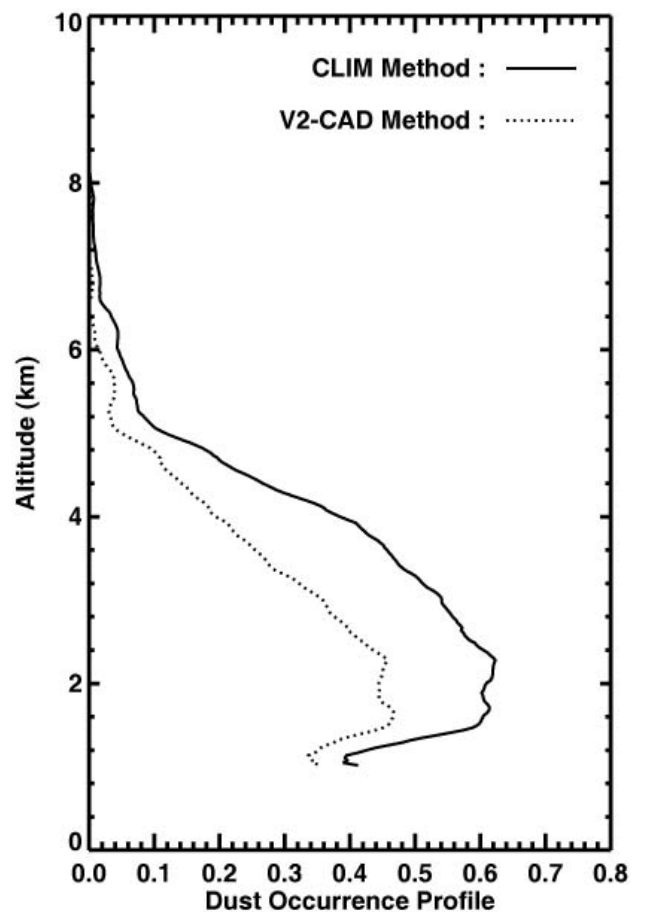

Fig. 10. Mean vertical profiles of dust aerosol occurrence from CALIPSO observations by V2-CAD method (dotted line), and CLIM (solid line) over Taklamakan desert for elevations below $3 \mathrm{~km}$ during spring 2008.

where $N_{e d}$ and $N_{e c}$ represent the number of segments in which cloud was misidentified as dust and dust as cloud by the detection method, respectively, and $N_{d}$ indicates the number of dust segments by Table 2 selection method.

The V2-CAD feature mask included the following eight feature types: $0=$ invalid ( $b a d$ or missing data), $1=$ clear air, $2=$ cloud, $3=$ aerosol, $4=$ stratospheric features, polar stratospheric cloud (PSC), or stratospheric aerosol, $5=$ surface, $6=$ subsurface, and $7=$ no signal (totally attenuated). Figure 7 shows that the V2-CAD method identified about $0.4 \%$ of the clouds (feature type $=2$ ) as dust and about $43.0 \%$ of the dust layers as clouds. Using the CLIM method, $3.8 \%$ of clouds were identified as dust and $3.2 \%$ of the dust layers were identified as clouds, as shown in Fig. 8 . The $R_{d}$, computed using Eq. (4), was $43.4 \%$ for the V2-CAD method and $6.7 \%$ for the CLIM method.

During the validation period, there were 234 segments of dust detected as cloud and 227 segments of cloud detected as dust by the CLIM method. Three clouds types were easy for CLIM to misclassify. These were thinner cloud, cloud mixed with dust, and the dust over cloud or underneath thin cloud.

For thin clouds, the BTD was affected by surface-emitted infrared radiation, and the lidar parameters were the same as those for the dense dust aerosol. Hence, thin clouds were identified as dense dust aerosols by the CLIM method. Future development of the CLIM method using individual 

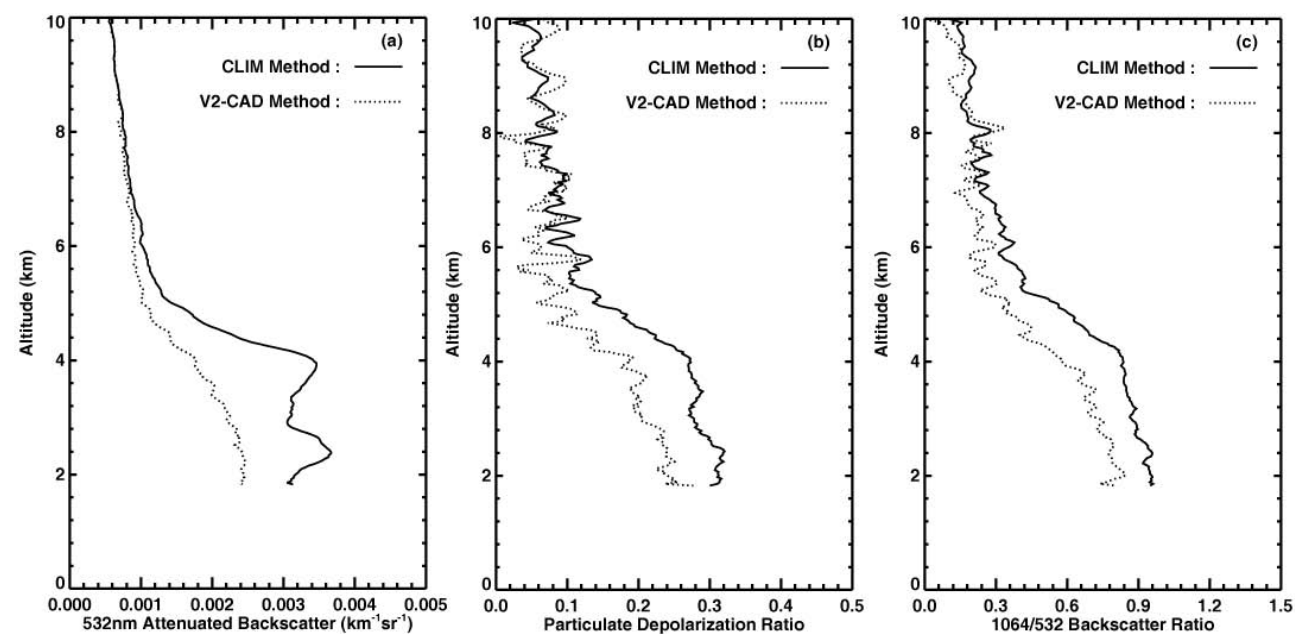

Fig. 11. Mean vertical profiles of dust aerosols over Taklamakan Desert using (a) 532-nm backscatter attenuated coefficients, (b) particulate depolarization ratio, and (c) 1064/532-nm backscatter ratio by V2-CAD method (dotted line), and CLIM (solid line) over Taklamakan Desert for elevationa below $3 \mathrm{~km}$ during spring 2008.

segments that cross $5 \mathrm{~km}$ will likely improve performance for this type of cloud, which often exists at the cloud edge and has a horizontal range of no more than $2 \mathrm{~km}$.

For dust aerosols over cloud and below thin cloud, the IIR and lidar parameters were the same, and cloud could not be distinguished from dust by the current single-layer CLIM method. This could be solved by future development of the CLIM method to identify multi-layer features. Cloud mixed with dust can be considered a new kind of layer feature that will be studied in the future.

\section{Dust occurrence and vertical structure}

The frequency of dust aerosol is defined as:

$\mathrm{OCC}_{i}=N_{i, \text { dust }} / N_{i}$

where $N_{i, \text { dust }}$ and $N_{i}$ is the number of single dust layer features and sum of the number of single layer features (including cloud and dust) and clear air in the vertical range $i$, respectively.

A comparison of latitude mean vertical distributions of dust layers over the Taklamakan Desert during spring 2008, derived by the V2-CAD and CLIM methods, is shown in Fig. 9. Both methods show dust decreasing significantly with altitude. The highest dust aerosol altitude was 6 and $8 \mathrm{~km}$ for the V2-CAD and CLIM method, respectively. The CLIM method, however, showed more dust and greater backscatter between altitudes of 1.8 to $6 \mathrm{~km}$.

As presented in Fig. 9a, the V2-CAD-detected dust occurrence for most levels is between $20 \%$ and $40 \%$, with only a few layers having frequencies greater than $40 \%$. However, dust occurrence identified by CLIM (Fig. 9b) is generally larger than $50 \%$ for levels between 1.8 and $4 \mathrm{~km}$. The CLIM method detected $10 \%$ more dust occurrence than the V2CAD method (Fig. 9c), especially for lower altitude ranges $(1.8$ to $4 \mathrm{~km}$ ) by about $20 \%$. Figure 10 shows the vertical profiles of the regionally averaged dust occurrence. It confirms the results discussed above. For altitudes in the range of 1.8 to $4 \mathrm{~km}$, the dust occurrence derived from CLIM exceeds that from V2-CAD by more than $18.3 \%$. This may be due to the fact that V2-CAD misidentified most of the dense dust layers in this range. At higher altitudes, such as 5 to $7 \mathrm{~km}$, the dust occurrence derived from CLIM was larger than that from V2CAD by only $3.1 \%$.

Figure 11 presents the vertical profiles of regionally averaged dust lidar parameters derived from CLIM (solid line) and from V2-CAD (dashed line) aerosol features over the Taklamakan Desert during spring, 2008. For the 532-nm backscatter attenuated coefficients (Fig. 11a), the vertical profile of CLIM is significantly larger, by 0.0011 , than that of V2-CAD for the 1.8 to $4 \mathrm{~km}$ range. There were two maximum peaks in this range. One peak is at $2.1 \mathrm{~km}$ with a maximum value of $0.0037 \mathrm{~km}^{-1} \mathrm{sr}^{-1}$ and the second is at $3.9 \mathrm{~km}$ with a value of $0.0035 \mathrm{~km}^{-1} \mathrm{sr}^{-1}$. The two vertical profiles are almost the same above $8 \mathrm{~km}$. For the particulate depolarization ratio (Fig. 11b), both vertical profiles decrease with altitude, but the CLIM values are much larger than the V2CAD values between 1.8 and $4 \mathrm{~km}$. The 1.8 to $4 \mathrm{~km}$ averaged CLIM value was 0.292 , which is $7.4 \%$ larger than that of V2-CAD. Similar results can be seen in Fig. 11c for the 1064/532-nm backscatter ratio. Both maximum ratios were found at $2 \mathrm{~km}$, with values of 0.99 (CLIM) and 0.84 (V2CAD). These results further demonstrate that CLIM detected much more dust between altitudes of 1.8 to $4 \mathrm{~km}$ over the source region than did V2-CAD. 


\section{Conclusions and discussion}

The recently launched CALIPSO satellite provides a wealth of actively collected data and an outstanding opportunity for studying dust aerosols. However, the current dust layer detection from the CALIPSO method based only on lidar measurements misclassified about $43 \%$ of dense dust layers over the Taklamakan Desert (estimated using currently released CALIPSO version 2 data). Although the fraction of the cloud and aerosol misclassification due to dense dust is very small in a global view, it can be high during active dust seasons over source regions. This paper presents a different approach that takes advantage of the simultaneous IIR and lidar measurements provided by CALIPSO. The new approach (CLIM) combines CALIOP observations to identify water clouds and thin dust aerosols with IIR BTDs to distinguish dense dust from ice clouds. The two test cases demonstrated that the CLIM method can detect dense dust that was misclassified as cloud by V2-CAD. The CLIM results were confirmed by other independent measurements from the ATrain satellites, CloudSat and MODIS, as well as from surface stations. The CLIM method results were validated using 2008 data. Results showed that the misclassified dust ratio $\left(R_{d}\right)$ of CLIM was much lower $(6.7 \%)$ than that of V2-CAD (43.4\%). This result indicates that the CLIM method not only can detect dust aerosols but can also more accurately identify clouds over the Taklamakan Desert during the daytime in spring.

The CLIM method also revealed more frequent dust occurrence and intensified backscatter between altitudes of 1.8 to $4 \mathrm{~km}$ over the source region compared to the current CALIPSO version-2 data. The CLIM method generally showed dust occurrence exceeding $50 \%$ in the 1.8 to $4 \mathrm{~km}$ altitude range. The height of the dust aerosols could reach $8 \mathrm{~km}$, allowing them to be transported via upper troposphere westerly jets (e.g., Uno et al., 2009). The dust intensities obtained from CLIM were larger than those from the lidar method. The seasonal mean 532-nm attenuated backscatter coefficients could exceed $0.0033 \mathrm{~km}^{-1} \mathrm{sr}^{-1}$, the particle depolarization was 0.292 , and the $1064 / 532$-nm backscatter ratio was 0.893 for the 1.8 to $4 \mathrm{~km}$ region.

This approach could be used in evaluating dust classification in the release 2 CALIPSO data products over and near source regions and for intercomparison of the release 3 dense dust classification. The latter uses a 5-D CAD scheme (with the additional dimensions of the volume depolarization ratio and latitude) that was developed and implemented by Liu (2009). Dense dust layers are well separated from clouds in the 5-D space of the version 3 data, planned for release in early 2010. The CLIM method also misclassified about $6.7 \%$ of the 2008 validation data. An error analysis showed that there were three misclassification scenarios: thinner cloud located near cloud edges, cloud mixed with dust, and dust aerosol layers above or underneath the cloud layer. Further research should use more surface observations, particularly lidar data, to validate the CLIM dust aerosol detection capability.

This paper represents the initial development of this technique. To test its application globally, the method should be tested for other dust source regions and during nighttime and different seasons, and for multi-layer features. Because it depends only on infrared measurements, it should be operable for both day and night conditions. For multi-layer dust or dust covered by cloud case, more sensor measurements may need to be integrated, such as microwave measurements (Huang et al., 2007b; Ge et al., 2008). By combining all the methods, it could be possible to overcome some of the weaknesses in techniques used alone.

Acknowledgements. This research is supported by National Science Foundation of China under grant (40725015, and 40633017) and by the NASA Science Mission through the CALIPSO Project and the Radiation Sciences Program. CloudSat data were obtained through the CloudSat Data Processing Center (http://www.cloudsat.cira.colostate.edu). CALIPSO data have been obtained from the Atmospheric Sciences Data Center (ASDC) at NASA Langley Research Center. The MODIS data were obtained from the NASA Earth Observing System Data and Information System, Distributed Active Archive Center (DAAC) at the GSFC.

Edited by: Q. Fu

\section{References}

Ackerman, S. A.: Remote sensing aerosols using satellite infrared observations, J. Geophys. Res., 102(D14), doi:10.1029/96JD03066, 17069-17079, 1997.

Albrecht, B. A.: Aerosols, cloud microphysics, and fractional cloudiness, Science, 245, 1227-1230, 1989.

Chen, Y., Mao, X., Huang, J., Zhang, H., Tang, Q., Pan, H., and Wang, C.: Vertical distribution characteristics of aerosol during a long-distance transport of heavy dust pollution, China Environ. Sci., 29(5), 449-454, 2009.

Chen, W., Dong, Z., Yang, Z., Han, Z., Zhang, J., Zhang, M.: The threshold wind velocity in the Taklamakan Desert, Acta Geographica Sinica, 7, 361-367, 1995.

Darmenov, A. and Sokolik, I. N.: Identifying the regional thermalIR radiative signature of mineral dust with MODIS, Geophys. Res. Lett., 32, L16803, doi:10.1029/2005GL023092, 2005.

El-Askary, H., Gautam, R., Singh, R. P., and Kafatos, M.: Dust storms detection over the Indo-Gangetic basin using multi sensor data, Adv. Space Res., 37, 4, 728-733, 2006.

Ge, J., Huang, J., Weng, F., and Sun, W.: Effects of dust storms on microwave radiation based on satellite observation and model simulation over the Taklamakan desert, Atmos. Chem. Phys., 8, 4903-4909, 2008, http://www.atmos-chem-phys.net/8/4903/2008/.

Generoso, S., Bey, I., Labonne, M., and Br'eon, F. M.: Aerosol vertical distribution in dust outflow over the Atlantic: comparisons between GEOS-Chem and Cloud-Aerosol Lidar and Infrared Pathfinder Satellite Observation (CALIPSO), J. Geophys. Res., 113, D24209, doi:10.1029/2008JD010154, 2008. 
Huang, J., Lin, B., Minnis, P., Wang, T., Wang, X., Hu, Y., Yi, Y., and Ayers, J. K.: Satellite-based assessment of possible dust aerosols semidirect effect on cloud water path over East Asia, Geophys. Res. Lett., 33, L19802, doi:10.1029/2006GL026561, 2006a.

Huang, J., Minnis, P., Lin, B., Wang, T., Yi, Y., Hu, Y., SunMack, S., and Ayers, K.: Possible influences of Asian dust aerosols on cloud properties and radiative forcing observed from MODIS and CERES, Geophys. Res. Lett., 33, L06824, doi:10.1029/2005GL024724, 2006b.

Huang, J., Minnis, P., Yi, Y., Tang, Q., Wang, X., Hu, Y., Liu, Z., Ayers, K., Trepte, C., and Winker, D.: Summer dust aerosols detected from CALIPSO over the Tibetan Plateau, Geophys. Res. Lett., 34, L18805, doi:10.1029/2007GL029938, 2007a.

Huang, J., Ge, J., and Weng, F.: Detection of Asia dust storms using multisensor satellite measurements, Remote Sens. Environ., 110, 186-191, 2007b.

Huang, J., Minnis, P., Chen, B., Huang, Z., Liu, Z., Zhao, Q., Yi, Y., and Ayers, J.: Long-range transport and vertical structure of Asian dust from CALIPSO and surface, J. Geophys. Res., 113, D23212, doi:10.1029/2008JD010620, 2008.

Huang, J., Fu, Q., Su, J., Tang, Q., Minnis, P., Hu, Y., Yi, Y., and Zhao, Q.: Taklamakan dust aerosol radiative heating derived from CALIPSO observations using the Fu-Liou radiation model with CERES constraints, Atmos. Chem. Phys., 9, 4011-4021, 2009, http://www.atmos-chem-phys.net/9/4011/2009/.

Husar, R. B., Tratt, D. M., Schichtel, B. A., Falke, S. R., Li, F., Jaffe, D., Gassó, S., Gill, T., Laulainen, N. S., Lu, F., Reheis, M. C., Chun, Y., Westphal, D., Holben, B. N., Gueymard, C., McKendry, I., Kuring, N., Feldman, G. C., McClain, C., Frouin, R. J., Merrill, J., DuBois, D., Vignola, F., Murayama, T., Nickovic, S., Wilson, W. E., Sassen, K., Sugimoto, N. and Malm, W. C.: Asian dust events of April 1998, J. Geophys. Res., 106(D16), 18317-18330, doi:10.1029/2000JD900788, 2001.

Iwasaka, Y., Minoura, H., and Nagaya, K.: The transport and spatial scale of Asian dust-storm clouds: a case study of the dust-storm event of April 1979, Tellus B, 35, 189-196, 1983.

Kim, S.-W., Berthier, S., Raut, J.-C., Chazette, P., Dulac, F., and Yoon, S.-C.: Validation of aerosol and cloud layer structures from the space-borne lidar CALIOP using a ground-based lidar in Seoul, Korea, Atmos. Chem. Phys., 8, 3705-3720, 2008, http://www.atmos-chem-phys.net/8/3705/2008/.

Legrand, M., Bertrand, J., and Desbois, M.: Dust clouds over West Africa: a characterization by satellite data, Ann. Geophys., 3, 777-784, 1985, http://www.ann-geophys.net/3/777/1985/.

Legrand, M., and N'doumé, C.: Satellite detection of dust using the IR imagery of Meteosat: 1. Infrared difference dust index, J. Geophys. Res., 106(D16), 18251-18274, doi:10.1029/2000JD900749, 2001.

Liu, D., Wang, Z., Liu, Z., Winker, D., and Trepte, C.: A height resolved global view of dust aerosols from the first year CALIPSO lidar measurements, J. Geophys. Res., 113, D16214, doi:10.1029/2007JD009776, 2008.

Liu, Z., Vaughan, M. A., Winker, D. M., Hostetler, C. A., Poole, L. R., Hlavka, D., Hart, W. and McGill, M.: Use of probability distribution functions for discriminating between cloud and aerosol in lidar backscatter data, J. Geophys. Res., 109, D15202, doi:10.1029/2004JD004732, 2004.

Liu, Z., Omar, A., Vaughan, M., Hair, J., Kittaka, C., Hu, Y., Pow- ell, K., Trepte, C., Winker, D., Hostetler, C., Ferrare, R., and Pierce, R.: CALIPSO lidar observations of the optical properties of Saharan dust: a case study of long-range transport, J. Geophys. Res., 113, D07207, doi:10.1029/2007JD008878, 2008.

Liu, Z., Vaughan, M., Winker, D., Kittaka, C., Getzewich, B., Kuehn, R., Omar, A., Powell, K., Trepte, C., and Hostetler, C.: The CALIPSO lidar cloud and aerosol discrimination: version 2 algorithm and initial assessment of performance, J. Atmos. Ocean. Techn., 26, 7, 1198-1213, 2009.

Mika, S., Rätsch, G., Weston, J., Schölkopf, B., and Müller, K.R.: Fisher discriminant analysis with kernels, Neural Networks Signal Proc, IEEE, 41-48, 1999.

Murayama, T., Sugimoto, N., Uno, I., Kinoshita, K., Aoki, K., Hagiwara, N., Liu, Z., Matsui, I., Sakai, T., Shibata, T., Arao, K., Sohn, B., Won, J.-G. Yoon, S.-C., Li, T., Zhou, J., Hu, H., Abo, M., Iokibe, K., Koga, R. and Iwasaka, Y.: Ground-based network observation of Asian dust events of April 1998 in east Asia, J. Geophys. Res., 106(D16), 18345-18359, doi:10.1029/2000JD900554, 2001.

Natsagdorj, L., Jugder, D., and Chung, Y. S.: Analysis of dust storms observed in Mongolia during 1937-1999, Atmos. Environ., 37, 1401-1411, 2003.

Platt, C. M. R., Winker, D. M., Vaughan, M. A., and Miller, S. D.: Backscatter-to-extinction ratios in the top layer of tropical mesoscale convective systems and in isolated cirrus from LITE observations, J. Appl. Meteorol., 38(9), 1330-1345, 1999.

Roskovensky, J. K., and Liou, K. N.: Detection of thin cirrus from $1.38 \mu \mathrm{m} / 0.65 \mu \mathrm{m}$ reflectance ratio combined with 8.6$11 \mu \mathrm{m}$ brightness temperature difference, Geophys. Res. Lett., 30, 1985, doi:10.1029/2003GL018135, 2003.

Roskovensky, J. K. and Liou, K. N.: Differentiating airborne dust from cirrus clouds using MODIS data, Geophys. Res. Lett., 32, L12809, doi:10.1029/2005GL022798, 2005.

Sassen, K.: Indirect climate forcing over the western US from Asian dust storms, Geophys. Res. Lett., 29, 1465, doi:10.1029/2001GL014051, 2002.

Shenk, W. E., and Curran, R. J.: The detection of dust storms over land and water with satellite visible and infrared measurements, Mon. Weather Rev., 102, 830-837, 1974.

Slingo, A., Ackerman, T. P., Allan, R. P., Kassianov, E. I., McFarlane, S. A., Robinson, G. J., Barnard, J. C., Miller, M. A., Harries, J. E., Russell, J. E., and Dewitte, S.: Observations of the impact of a major Saharan dust storm on the atmospheric radiation balance, Geophys. Res. Lett., 33, L24817, doi:10.1029/2006GL027869, 2006.

Su, J., Huang, J., Fu, Q., Minnis, P., Ge, J., and Bi, J.: Estimation of Asian dust aerosol effect on cloud radiation forcing using $\mathrm{Fu}-$ Liou radiative model and CERES measurements, Atmos. Chem. Phys., 8, 2763-2771, 2008, http://www.atmos-chem-phys.net/8/2763/2008/.

Stephens, G. L., Vane, D. G., Boain, R. J., Mace, G. G., Sassen, K., Wang, Z., Illingworth, A. J., O'Connor, E. J., Rossow, W. B., Durden, S. L., Miller, S. D., Austin, R. T., Benedetti, A., Mitrescu, C., and Team, T. C. S.: The CLOUDSAT mission and the A-train, B. Am. Meteorol. Soc., 83, 1771-1790, 2002.

Tegen, I.: Modeling the mineral dust aerosol cycle in the climate system, Quat. Sci. Rev., 22, 19, 1821-1834, 2003.

Twomey, S. A., Piepgrass, M., and Wolfe, T. L.: An assessment of the impact of pollution on global cloud albedo, Tellus B, 36, 
356-366, 1984

Uno, I., Amano, H., Emori, S., Kinoshita, K., Matsui, I., and Sugimoto, N.: Trans- Pacific yellow sand transport observed in April 1998: a numerical simulation, J. Geophys. Res., 106(D16), 18331-18344, doi:10.1029/2000JD900748, 2001.

Uno, I., Eguchi, K., Yumimoto, K., Takemura, T., Shimizu, A., Uematsu, M., Liu, Z., Wang, Z., Hara, Y., and Sugimoto, N.: Asian dust transported one full circuit around the globe, Nat. Geosci., 2, 557-560, doi:10.1038/ngeo583, 2009.

Vaughan, M., Young, S., Winker, D., Powell, K., Omar, A., Liu, $\mathrm{Z}$., Hu, Y., and Hostetler, C.: Fully automated analysis of spacebased lidar data: an overview of the CALIPSO retrieval algorithms and data products, Proc. SPIE Int. Soc. Opt. Eng., 5575, 16-30, 2004.

Winker, D. M. and Vaughan, M. V.: Vertical distribution of clouds over Hampton, Virginia observed by lidar under the ECLIPS and FIRE ETO programs, Atmos. Res., 34, 117-133, 1994.

Winker, D. M., Couch, R. H., and McCormick, M. P.: An overview of LITE: NASA's Lidar In-Space Technology Experiment, Proc. IEEE, 84(2), 164-180, 1996.
Winker, D. M., Hunt, W. H., and Hostetler, C. A.: Status and performance of the CALIOP lidar, Proc. SPIE Int. Soc. Opt. Eng., $5575,8-15,2004$.

Winker, D., Pelon, J., and McCormick, M.: Initial results from CALIPSO, 23rd International Laser Radar Conference, Nara, Japan, 2006.

Winker, D., Hunt, W., and McGill, M.: Initial performance assessment of CALIOP, Geophys. Res. Lett., 34, L19803, doi:10.1029/2007GL030135, 2007.

Zhang, P., Lu, N. M., Hu, X. Q., and Dong, C. H.: Identification and physical retrieval of dust storm using three MODIS thermal IR channels, Global Planet. Change, 52(1-4), 197-206, 2006.

Zhang, X. Y., Arimoto, R., and An, Z. S.: Dust emission from Chinese desert sources linked to variations in atmospheric circulation, J. Geophys. Res., 102(D23), 28041-28047, doi:10.1029/97JD02300, 1997. 